low-status victims' emergencies were reported more quickly than those of high-status victims, casts considerable doubt on our initial assumption about the relationship between status, rewards and costs, and aiding. Another possibility is that our manipulation of status (high status = first-year graduate student. low status = freshman) might not have had the desired impact. However, the postquestionnaire data indicate that the high-status victim was rated as slightly more intelligent $(F=2.44$, df $=1.40$, $.10<\mathrm{p}<20$ ) and as significantly more likable than the low-status victim $(F=4.73, \mathrm{df}=1,40, \mathrm{p}<.05)$.

Thus. the data bolster our confidence in the existence of the phenomenon of decreased aiding as a function of increasing group size, while at the same time raising further questions about the generality of the phenomenon and the dynamics which underlie it.

\section{REFERENCES}

Darley, J. M., \& Latané, B. Bystander interventio1. in emergencies: Diffusion of responsibility. Journal of Personality \& Social Psychology, 1968, 8, 377-383.

Latané, B., \& Darley, J. M. Bystander "apathy." American Scientist, $1969,57,244-268$.

Mogy, R. B., \& Harris, V. A. Factors influencing the development of altruistic behavior: $A$ review and reconceptualization. Unpublished manuscript, State University of New York at Buffalo, 1971.

(Received for publication April 23, 1973.)

\title{
Keypecking by pigeons in an imperfect environment for autoshaping
}

\section{R. M. GILBERT \\ Addiction Research Foundation, Toronto, Ont., Canada}

Keypecking under the usual autoshaping procedure was found to be less likely when the key light was unshielded and thus allowed autoshaping to a stimulus available inside the food magazine alcove. Some birds pecked, nevertheless, mostly near the beginning of the stimulus rather than near the end, when autoshaped keypecking usually occurs. Regular autoshaped keypecking can be explained in terms of respondent conditioning, even though the resulting behavior may not be advantageous to the pigeon. Pecking at the beginning of the stimulus, which precedes autoshaped behavior directed towards the food alcove, may require an explanation in terms of higher-order conditioning.

Pigeons are apt to peck a lighted key that signals food. The phenomenon was first explored systematically by Brown \& Jenkins (1968), who dubbed the process leading to the first peck "autoshaping." Moore (1971) reported informally that keypecking may not be autoshaped if the lamp that transilluminates the key is imperfectly shielded. He noted that lack of shielding could have been a factor in the results of a study by ten Cate (1923), who, according to Moore, was probably the first $E$ to expose pigeons to an autoshaping procedure. ten Cate's pigeons did not peck the key, or rather its equivalent. Instead they put their heads into the food alcove when the light came on, making what Moore described as anticipatory responses. Much to our annoyance, we made a similar finding, quite independently. During an autoshaping study, our pigeons persistently put their heads in the food hopper opening when, to be consistent with the Brown and Jenkins result, they should have been pecking the key. A subsequent comparison between birds that had a shielded lamp and birds that had an unshielded lamp showed clearly that the shielding facilitated keypecking. This comparison is reported here.

\section{METHOD \\ Subjects and Apparatus}

Eighteen 3-year-old male White Carneaux pigeons, experimentally naive and obtained 6 months earlier from the Palmetto Pigeon Plant, Sumpter, S.C., had been maintained at close to $80 \%$ of their respective free-feeding weights for about 3 months.

Three identical experimental chambers were used. Within each was a standard LeHigh Valley three-key "pigeon intelligence panel" (No.141-13), slotted into a chamber of the same dimensions as the Lehigh Valley Model 132-02. The two outside keys were taped over and unused. The center key was opaque and could be transilluminated by a bare $2.2-\mathrm{W}$ bulb, $25 \mathrm{~mm}$ behind the key. The bulb and its support could be totally enclosed by a black box that fitted snugly against the rear of the panel around the key and its supporting fixture. Across the 
Table 1

Summary Data from Two Groups of Six Birds Each for Which the Stimulus Predicted Food

\begin{tabular}{|c|c|c|c|c|c|c|c|c|}
\hline & \multirow{3}{*}{$\begin{array}{l}\text { Trial } \\
\text { of } \\
\text { First } \\
\text { Peck }\end{array}$} & \multicolumn{3}{|c|}{$\begin{array}{l}\text { Total Pecks During } \\
\text { Final } 48 \text { Trials }\end{array}$} & \multicolumn{4}{|c|}{$\begin{array}{l}\text { Percentage of Time Spent With Head } \\
\text { in Magazine During Final } 48 \text { Trials }\end{array}$} \\
\hline & & \multirow{2}{*}{$\begin{array}{l}\text { During } \\
\text { Inter- } \\
\text { trial } \\
\text { Interval }\end{array}$} & \multicolumn{2}{|c|}{ During Stimulus } & \multirow{2}{*}{$\begin{array}{c}4 \mathrm{Sec} \\
\text { Before } \\
\text { Stimulus }\end{array}$} & \multicolumn{2}{|c|}{ During Stimulus } & \multirow{2}{*}{$\begin{array}{l}\text { During } \\
\text { Food } \\
\text { Presen- } \\
\text { tation }\end{array}$} \\
\hline & & & $\begin{array}{l}\text { First } \\
\text { Half }\end{array}$ & $\begin{array}{l}\text { Second } \\
\text { Half }\end{array}$ & & $\begin{array}{l}\text { First } \\
\text { Half }\end{array}$ & $\begin{array}{l}\text { Second } \\
\text { Half }\end{array}$ & \\
\hline & 2 & 15 & 174 & 274 & - & - & - & 62 \\
\hline These six birds had & 13 & 18 & 182 & 257 & - & - & - & 63 \\
\hline a shielded stimulus & 65 & 22 & 244 & 526 & - & - & - & 73 \\
\hline lamp, i.e., no light & 17 & - & - & - & - & - & - & 44 \\
\hline \multirow[t]{3}{*}{ got to magazine area } & 51 & 15 & 155 & 271 & - & - & - & 64 \\
\hline & 24 & 14 & 266 & 359 & - & - & - & 64 \\
\hline & Mean & 14 & 170 & 281 & - & - & - & 62 \\
\hline \multirow{7}{*}{$\begin{array}{l}\text { These six birds had an } \\
\text { unshielded lamp, i.e., } \\
\text { light was getting to } \\
\text { magazine area }\end{array}$} & $\mathrm{x}$ & - & - & - & - & 35 & 75 & 93 \\
\hline & 61 & - & 1 & - & 1 & 29 & 97 & 98 \\
\hline & 59 & - & 82 & 18 & - & 12 & 41 & 88 \\
\hline & 76 & 83 & 80 & 36 & 6 & 29 & 48 & 85 \\
\hline & 89 & 2 & 11 & 15 & 5 & 18 & 35 & 55 \\
\hline & $\mathrm{x}$ & - & - & - & 1 & 27 & 69 & 87 \\
\hline & Mean & 14 & 29 & 12 & 2 & 25 & 60 & 84 \\
\hline
\end{tabular}

entrance to the food hopper of each chamber was a photocell unit, the dim light of which was continuously on. Masking noise was provided by the panel speakers and the extractor fans. The standard houselight in each box was on continuously except during grain presentations, when a lamp inside the food hopper came on. Stimulus (key light) and food presentations were arranged by a paper-tape reader in a neighboring room, supplemented by solid state modules, chart recorders, and electromagnetic counters that recorded keypecks and interruptions of the photocell beams.

\section{Procedure}

Each bird had been in one of the experimental chambers for $1 \mathrm{~h}$ and had eaten grain from the hopper there for $1 \mathrm{~min}$ prior to the one experimental session. During this familiarization procedure, no bird experienced either a stimulus or a food hopper presentation. Birds were withdrawn from the chamber while the hopper was raised. The 18 birds were divided arbitrarily into three groups of six each.

The birds were run in six batches of three birds each. In each of the first four batches, one or two birds had an unshielded key lamp and for the remainder the lamp was shielded. Thus arranged, one group of six birds had an unshielded lamp and another group of six birds had a shielded lamp, each chamber being used by two birds of each group.

For these two groups, the one experimental session comprised 148 trials, each consisting of an 8-sec key-light presentation followed immediately by a 3.4-sec grain presentation. Intervals between subsequent key-light onsets varied between 24 and $80 \mathrm{sec}$, with a mean of $52 \mathrm{sec}$.

The third group of six birds was run in the two final batches, all with an unshielded lamp. As for the two other groups, the one experimental session comprised 148 trials, each consisting of an 8-sec stimulus and a 3.4-sec grain presentation. However, for this group, the stimuli were presented midway between grain presentations, which occurred according to the schedule that applied to the other two groups. Thus, the mean stimulus offset to grain-presentation interval for this group was $22 \mathrm{sec}$, with a range of 8-36 sec.

\section{RESULTS AND DISCUSSION}

The birds in the group for which the stimulus did not predict food neither pecked nor put their heads into the magazine alcove, except when grain was available. During grain presentations, the proportions of time that these birds had their heads in the magazine were $68 \%$, $74 \%, 59 \%, 76 \%, 81 \%$, and $74 \%$, respectively, with a mean of $72 \%$.

Table 1 provides data from the two groups for which the stimulus predicted food. It shows that the birds that had the shielded stimulus lamp tended to keypeck earlier and then more frequently than the birds that had the unshielded lamp. However, the most dramatic difference between these two groups lay in the incidence of photocell interruptions. These indicated that the bird had its head in the food magazine. Except at the beginning of the session, the birds in the group that had the shielded stimulus lamp put their heads in the magazine only when food was available, and kept it there for, on the average, only $62 \%$ of the available time (based on the last 48 trials of the session). By contrast, the birds in the other group regularly put their heads in the magazine during stimulus presentations. Furthermore, during food presentations, this behavior occupied $84 \%$ of the available time, on the average.

The birds in the group with unshielded lamps tended to peck more in the second $4 \mathrm{sec}$ of the stimulus duration than during the first $4 \mathrm{sec}$. The other birds likewise had their heads in the magazine more during the second half of the stimulus. The two birds with the unshielded key that emitted substantial amounts of pecking both pecked more in the first half of the stimulus. These two birds developed a pattern, obvious in the chart records, that included pecking the key when it was illuminated and then putting their heads in the magazine.

The birds with the unshielded lamp had their heads in the magazine during food presentation more, on the average, than the birds in the other group. Making the 
reasonable assumption that they were eating during this time, it is clear that the birds with the unshielded lamp were emitting behavior that was more appropriate to the situation. The source of the appropriateness is fairly obvious. Birds that had a shielded lamp were usually pecking the key when the food was presented, and had to spend a considerable portion of the food presentation period merely getting into an eating position. The birds in the other group, by contrast, were generally well prepared to eat from the onset of food presentation, because their heads were usually already in the magazine. The real problems are to explain why the birds with the shielded lamps pecked in such an unadaptive way, and why the lack of shielding caused the other birds to behave differently.

Moore (1971) argued that autoshpaing is a respondent conditioning phenomenon, and that respondent conditioning comprises stimulus substitution to the extent that the conditioned stimulus assumes the properties of the unconditioned stimulus. Autoshaping follows directly from this account of respondent conditioning. The pigeons keypeck because, as a result of the pairings of key light and food presentation, the key acquires the properties of food and elicits pecks accordingly. This interpretation accommodates two important results concerning autoshaping. Moore's own finding, that keypecking autoshaped with a water UCS resembles drinking wheras keypecking autoshaped with a food UCS resembles eating, is entirely consistent with the notion of stimulus substitution. The other finding, by Williams \& Williams (1969), is that pigeons continue to peck when the autoshaping procedure is continued, even if pecks prevent food delivery. This finding is accommodated by assuming that the infrequent pairings that result from such a procedure are nevertheless sufficient to maintain the property of the key to elicit pecking, at least on some presentations. Given the above, no further account is needed of the keypecking by the birds that had the shielded lamps in the present situation, except for the necessary assumption that the onset of the key light was a sufficient stimulus for respondent conditioning to occur. The existence of the respondent conditioning mechanism must be accounted for in phylogenetic terms.

It seems that birds and some other organisms have evolved in such a way that a stimulus that predicts another stimulus acquires the behavior-eliciting properties of the other stimulus. Presumably this inherited mechanism confers an advantage to organisms that embody it. For a pigeon, it might enable pecking to be elicited by food at a distance as well as by proximal food, and threat to be elicited by the sound as well as the sight of another pigeon. The mechanism broadens the scope of the pigeon's sensitivity to the environment, usually producing behavior that is anticipatory, preparing the pigeon for contact with an important environmental event. Occasionally, however, the mechanism is maladaptive, as in the usual autoshaping procedure. Behavior elecited by predictive stimuli may prevent some or all of the behavior that is necessary for survival. Natural examples are few, because persistent deception by the natural environment is rare. Predictive stimuli usually bear an intimate relation to the stimuli they predict. Furthermore, responses to predictive stimuli are invariably facilitative, rather than incompatible, as in autoshaping, or actually preventive, as in the experiment by Williams \& Williams (1969) mentioned earlier.

The autoshaping situation with the unshielded lamp, as described here, is probably a closer approximation to the natural environment than the regular autoshaping situation, because it provided a predictive stimulus that was close to the locus of food. This was discovered by inspecting the interior of the magazine alcove with a dentist's mirror. The stimulus lamp illuminated a part of the floor of the chamber that was behind the panel and visible to the pigeon through the hole in the bottom of the alcove where grain was presented. Presumably pecking became autoshaped to this stimulus, ensuring that a pigeon so controlled was well prepared to eat when grain was presented.

Although the six pigeons with the unshielded lamp and the predictive stimulus were probably autoshaaped to the patch of light on the floor, it is interesting to note that four of them pecked, two consistently enough for a keypeck $\rightarrow$ head-in-magazine sequence to be recognized. Pecking in each case developed after the head-in-magazine behavior had become stabilized, with the latter behavior occurring predominantly in the second half of the stimulus. It is likely that this latter behavior was now being elicited by a conditional stimulus, comprising both patch on floor and time since key light onset. This process of conditional control rendered the pigeons free to peck the key itself at the beginning of the stimulus. Why some of these birds keypecked is another matter, however. Presumably the key light elicited pecking because it reliably preceded the illuminated floor patch or grain presentation, or both. If the key light acquired its property because it was paired with the floor patch, the temporal sequencing being provided by the pigeon, keypecking by these two birds at the beginning of the stimulus interval provided an instance of higher-order respondent conditioning.

\section{REFERENCES}

Brown, P. L., \& Jenkins, H. M. Autoshaping of the pigeon's key peck. Journal of the Experimental Analysis of Behavior, 1968, $11,1-8$.

Moore, B. R. On directed respondents. Unpublished PhD thesis, Stanford University, 1971.

ten Cate, J. Essai d'étude des fonctions de l'éforce cérébrale des pigeons par la methode des réflexes conditionels. Archives Néerlandaises de Physiologie de l'Homme et des Animaux, $1923,8,234-273$

Williams, D. R., \& Williams, H. Automaintenance in the pigeon: Sustained pecking despite contingent non-reinforcement. Journal of the Experimental Analysis of Behavior, 1969, 12, 511-520.

(Received for publication April 15, 1973.) 